\title{
REVERBERAÇÕES DE APRENDIZAGENS SOBRE MEDIDAS NA PRÁTICA DE PROFESSORES QUE ENSINAM MATEMÁTICA
}

\author{
REPERCUSSIONS OF LEARNING ABOUT MEASURES INTO THE \\ PRACTICE OF TEACHERS WHO TEACH MATHEMATICS \\ REPERCUSIONES DE APRENDIZAJE ACERCA DE LAS MEDIDAS EN LA
PRÁCTICA DE LOS PROFESORES QUE ENSEÑAN MATEMÁTICAS
}

\author{
Alessandra Rodrigues de Almeida \\ Professora Doutora da Pontifícia Universidade Católica de Campinas (PUC-CAMPINAS). \\ Campinas-SP, Brasil \\ alessandra.almeida@puc-campinas.edu.br \\ Maria Auxiliadora Bueno Andrade Megid \\ Professora Doutora da Pontifícia Universidade Católica de Campinas (PUC-CAMPINAS). \\ Campinas-SP, Brasil \\ dmegid@puc-campinas.edu.br
}

\begin{abstract}
Resumo: Este artigo apresenta uma investigação a respeito de práticas pedagógicas desenvolvidas, por professores da Educação Infantil e dos Anos Iniciais do Ensino Fundamental em formação continuada, num grupo de estudos com características colaborativas que discute o ensino e a aprendizagem da Matemática. Com o objetivo de discutir as reverberações das aprendizagens dos estudos em colaboração nas práticas docentes a respeito do tema Grandezas e Medidas, o texto foca, especificamente, as práticas de dois dos participantes em relação à medida das grandezas comprimento e tempo. Os dados foram produzidos a partir de videogravações de encontros do grupo e de narrativas escritas pelos professores. A pesquisa se desenvolveu numa perspectiva qualitativa, valorizando a descrição dos encontros, da participação dos professores e das interações ocorridas no contexto do grupo e das instituições educacionais onde os professores atuam. $\mathrm{O}$ enquadramento metodológico e os procedimentos de análise adotados estão de acordo com a pesquisa narrativa, como um modo de compreender a experiência vivenciada no grupo e com ele. A participação no grupo de estudos possibilitou aos docentes aprendizagens conceituais sobre as Grandezas e Medidas, e sobre seu ensino e aprendizagem nos anos iniciais da educação básica. Tais aprendizagens reverberaram nas práticas dos participantes, tornando-as mais exploratórias e problematizadoras, por meio da inserção do tema e/ou de alterações graduais nas maneiras de abordá-lo com crianças.
\end{abstract}

Palavras-chave: Educação matemática. Grandezas e medidas. Práticas docentes. Grupos colaborativos.

\begin{abstract}
This article presents an investigation regarding pedagogical practices developed, by kindergarten and early Elementary School teachers in continuous education, in a study group with collaborative characteristics that discusses teaching and learning Mathematics. Aiming to discuss the repercussions of the learning from collaborative studies in teaching practices regarding the subject of Measurements and Quantities, the text focuses, specifically, on the practices of two of the participants in relation to the measurement of the quantities time and length. The data was produced from video recordings of the group meetings and narratives written by the teachers of the group. The research was developed in a qualitative perspective, valuing the description of the meetings, participation of the teachers and interactions that occurred in the context of the group and educational institutions where the teachers work. The methodological framework and adopted analysis procedures are in accordance with narrative research as a way of understanding the experience lived in and with the group. The participation in the study group allowed teachers' conceptual learning about Measurements and Quantities, as well as about their teaching and learning in the early years of basic education. Such learning reverberated into the practices of the participants, making them more exploratory and problematizing, through the insertion of the theme and / or gradual changes in the ways of approaching it with children.
\end{abstract}

Keywords: Mathematics education; Measurements and quantities; Teaching practices; Collaborative groups.

Resumen: Este artículo presenta una investigación acerca de las prácticas pedagógicas desarrolladas por maestros de educación infantil y escuela primaria en educación continua en el estudio del grupo de investigación con características colaborativas que debaten la enseñanza y aprendizaje de las matemáticas. El texto se centra específicamente en las prácticas desarrolladas por dos de los participantes en relación con la medida de longitud y tiempo. El objetivo es discutir las repercusiones del aprendizaje de los estudios de colaboración en la enseñanza de las prácticas en relación con el tema de las medidas y cantidades. Los datos se produjeron de videos grabados de las reuniones y narraciones escritas por los profesores del grupo. La investigación se desarrolló en la perspectiva cualitativa, valorando la descripción de las reuniones, la participación de los docentes y las interacciones que pasaran en el contexto del grupo y de las 
instituciones educativas donde trabajan los maestros. Los procedimientos de análisis y metodología adoptados están de acuerdo con la investigación narrativa como una forma de entender que la experiencia vivida en el grupo y con él El análisis del proceso de formación indica que la participación en el grupo de estudio ha permitido a los docentes el conceptual aprendizaje sobre las medidas y cantidades, así como sobre su enseñanza y el aprendizaje en los primeros años de educación básica. Este aprendizaje ha repercutido en las prácticas de los participantes, haciéndolas más exploratorias y problematizadas, a través de la inserción de los cambios de tema y/o alteraciones graduales de las formas de lo abordar con niños.

Palabras clave: Educación matemática; Medidas y cantidades; Prácticas de enseñanza; Grupos

\section{INTRODUÇÃO}

O tema Grandezas e Medidas está presente no cotidiano das pessoas desde a infância. É comum observarmos, em situações de brincadeiras, as crianças medindo distâncias, estimando tempo, verificando quais objetos consegue carregar, enchendo e esvaziando recipientes com água, areia, entre muitas outras ações. A atitude de medir nos acompanha durante toda a vida; é algo que fazemos todos os dias.

Entretanto, embora as medidas estejam presentes no dia a dia de crianças e adultos, elas são um tema matematicamente crítico na Educação Infantil e nos Anos Iniciais do Ensino Fundamental. Em algumas situações, grandezas e medidas são trabalhadas apenas no $4 .^{\circ}$ e no $5 .^{\circ}$ anos do Ensino Fundamental e seu estudo foca as unidades e os instrumentos padronizados, bem como as transformações das unidades de mesma grandeza, sem necessariamente promover a compreensão a respeito do tema (SILVA, 2011). Nessa mesma perspectiva, Cunha (2008) salienta que as atividades de medição de grandezas desenvolvidas pelas escolas trabalham mais diretamente a medição do tempo e de grandezas padronizadas, como comprimento, superfície e volume, sem considerar o aspecto da comparação, necessário ao "pensar medida" e ao "fazer medida".

Tal situação pode ocorrer em virtude da pouca formação que os professores detêm

no contexto da Geometria e das Grandezas e Medidas (NYE; KONSTANTOPOULOS; HEDGES, 2004) e também por ser a ideia de medida ainda associada quase exclusivamente à manipulação de signos e instrumentos, sem sentido e sem significado para professores e alunos.

Diante da problemática do ensino e da aprendizagem das Grandezas e Medidas no início da Educação Básica, entendemos como fundamental a inserção e/ou a ampliação desse tema na formação (inicial e continuada) de professores, de modo a possibilitar o conhecimento matemático e didático, para abordá-lo com seus alunos.

Consideramos que os grupos de estudos com características colaborativas se configuram como espaços importantes de formação docente e de produção de conhecimentos a respeito do ensino e da aprendizagem da Matemática na Educação Básica. Desse modo é relevante investigar como as aprendizagens ocorridas nesses contextos, a respeito das grandezas e medidas, efetivamente reverberam nas práticas desenvolvidas na escola.

É importante enfatizar que a reverberação é um conceito que tem origem na Física, compreendido como a persistência de um som audível após a cessação desse mesmo som em sua fonte produtora. Aqui utilizamos o termo com base nas ponderações de Crecci $(2016, p$. 276), que relaciona a reverberação "ao fenômeno que se propaga ou à ação de refletir". Nesse sentido, buscamos identificar situações de aprendizagem que possibilitem mudanças ou que sejam incorporadas às práticas de ensinar e aprender Matemática pelos participantes do grupo, ou em situações em que as discussões realizadas em encontros presenciais reverberam em outras situações, como nas interações virtuais entre os participantes.

Com base nessas considerações, apresentamos um recorte dos resultados de uma investigação que envolveu o estudo, a elaboração e a discussão de práticas a respeito das grandezas e medidas no âmbito do Grupo de Estudos Professores Matematizando nos Anos Iniciais - GEProMAl. Neste texto abordamos as reverberações das aprendizagens em grupo nas práticas dos professores, destacando as medidas de comprimento, na Educação Infantil, e de tempo, no Ensino Fundamental.

\section{A FORMAÇÃO MATEMÁTICA DO PROFESSOR DA INFÂNCIA}

$\mathrm{Na}$ investigação desenvolvida denominamos professores da infância os docentes que lecionam no início da Educação Básica, pois estes são os responsáveis pelo ensino e pela aprendizagem da 
Matemática na Educação Infantil e anos iniciais do Ensino Fundamental. No Brasil, a habilitação necessária ao professor para atuar nessas etapas educacionais é a graduação em Pedagogia, no entanto, em outros momentos, era possível a formação inicial do professor por meio de cursos como o Ensino Médio - Magistério ${ }^{1}$ e Normal Superior ${ }^{2}$.

Historicamente a formação dos professores no Brasil é marcada pelo pouco prestígio, por escassos recursos financeiros e políticas descontínuas, permeadas por constantes reformas (SAVIANI, 2008). Tais circunstâncias promovem dificuldades que vão se perpetuando indefinidamente.

A formação inicial de professores deveria ser favorecida com excelentes subsídios, uma vez que ali começam a se constituir as bases para a futura profissionalização docente (PESCE; ANDRÉ, 2012). Se assim ocorrer, haverá mais espaço e incentivo para o aperfeiçoamento profissional e para as práticas reflexivas.

A formação inicial deveria configurar-se em alicerce sólido para a constituição da profissão do professor, neste caso da Educação Infantil e dos anos iniciais do Ensino Fundamental, início da escolarização de grande parte das pessoas e, portanto, de máxima importância na vida de cada estudante.

Gatti, Barreto e André (2011) indicam a necessidade de uma avaliação da forma como os cursos de Pedagogia estão desenvolvendo seus currículos e investindo na formação desses profissionais: criam bases sólidas ou deixam lacunas na formação deles? E a pesquisa de Gatti e Barreto (2009) sobre os desafios encontrados na formação de professores no Brasil afirma haver, nos cursos investigados, pouca clareza na definição das áreas do conhecimento necessárias para atuar na Educação Básica: o licenciado fica entre duas formações distintas, a do professor ou a do especialista. Professor de matemática ou Matemático? Professor de Ciências ou Biólogo? Esse desafio para aqueles que estudam a formação de professores.

A mesma discussão é também presente nas licenciaturas e se estabelece no âmbito dos currículos dos cursos de pedagogia: quais componentes curriculares devem ser abordados? Que profissional se pretende formar? Professores para os anos iniciais ou especialistas da educação? Gatti e Barreto (2009) indica que há a necessidade de integração entre as disciplinas específicas, a formação educacional geral e didática que considerasse o nível de ensino. Outro fator indicado pelo mesmo estudo foi a necessidade de formadores preparados para realizar a formação de professores, com intenção de centrar-se em um novo conceito de profissionalização, que contemple uma proposta de um continuum de formação.

Conforme asseguram Nacarato, Mengali e Passos (2009), é grande o desafio que enfrentam os professores da infância para ensinar o que nem sempre aprenderam. Embora propostas construtivistas venham sendo apresentadas, ainda predomina, nas tendências didático-pedagógicas, a ênfase em conteúdos específicos, o que pouco contribui às discussões metodológicas relacionadas à matemática.

Curi (2005) analisou ementas de cursos - disponíveis em seus sites na Internet - de algumas instituições formadoras de professores polivalentes das disciplinas da área de matemática em cursos de Pedagogia do estado de São Paulo e encontrou diferenças, no que tange às suas nomenclaturas, à carga horária e ao perfil do docente formador. Na maioria das vezes (66\% dos casos), o curso recebe o nome de Metodologia da Matemática, sua centralidade está na discussão relacionada ao "como fazer", ou seja, nos aspectos metodológicos, e não transparecem como importantes os aportes teóricos ou o conhecimento do conteúdo.

Como temas mais frequentes, estão indicados: a construção do número e as quatro operações com números naturais e racionais, porém aspectos relacionados à geometria e a medidas e tratamento da informação são praticamente desconsiderados.

Podemos depreender, das consultas à literatura, que os professores dos anos iniciais, em grande parte dos casos, replicam suas experiências como alunos nos anos iniciais (ZEICHNER, 1984; NACARATO; MENGALI; PASSOS, 2009; MEGID, 2009).

De outra parte, é importante afirmar que, se existe clareza de que a formação inicial é de fato inicial, finalizar um curso de graduação não é suficiente, embora necessário, para uma boa prática profissional (DAY, 2005). [Entretanto, tal formação não pode ser compreendida numa perspectiva

1 A habilitação específica de $2^{\circ}$ grau para o exercício do magistério de $1^{\circ}$ grau (HEM) foi instituída pelo parecer MEC n. 349/72 (BRASIL, 1972). Em 1982, foi lançado o projeto de criação dos Centros de Formação e Aperfeiçoamento do Magistério (CEFAM) que também habilitavam para o magistério em $2^{\circ}$ grau (SAVIANI, 2009).

2 De acordo com o Parecer CNE 115/999, o Curso Normal Superior foi criado com o intuito de formar profissionais para atuarem no magistério da Educação Infantil e anos iniciais do Ensino Fundamental (BRASIL, 1999). 
de preencher as muitas lacunas decorrentes de uma formação inicial inconsistente, nem tampouco como de acúmulo de conhecimentos ou de complementaridade do sujeito, mas a possibilidade de participação em diferentes momentos e espaços em que professores possam aprender e se desenvolver profissionalmente.]

A formação que ocorre após a graduação, na perspectiva indicada por Passos et al. (2006), se apresenta como algo contínuo, que ocorre ao longo da vida e de modo integrado às práticas sociais e cotidianas de cada professor. Os autores consideram a formação docente:

[...] numa perspectiva de formação contínua e de desenvolvimento profissional, pois pode ser entendida como um processo pessoal, permanente, contínuo e inconcluso que envolve múltiplas etapas e instâncias formativas. Além do crescimento pessoal ao longo da vida, compreende também a formação (teórico-prática) da formação inicial — voltada para docência e que envolve aspectos conceituais, didático-pedagógicos e curriculares - e o desenvolvimento e a atualização da atividade profissional em processos de formação continuada após a conclusão da licenciatura (PASSOS et al., 2006, p. 195).

A formação docente, na concepção dos autores, é compreendida numa perspectiva ampla: desenvolve-se durante a vida profissional, vai além das atividades acadêmicas dos cursos e ocorre também a partir das interações entre os profissionais na escola, das reflexões sobre a prática pedagógica, das pesquisas para o desenvolvimento das aulas, da participação em encontros e discussões em grupos em diferentes momentos. Portanto, a participação de professores em grupos com características colaborativas pode promover a formação docente numa perspectiva de desenvolvimento profissional, e permitir ao professor reconhecer-se como produtor de conhecimentos e como agente de mudança nos contextos educacionais onde está inserido (COCHRAN-SMITH, 2012; SARAIVA; PONTE, 2003).

Compreender o professor como agente de mudança implica reconhecer seu papel no processo de transformação da realidade da escola (e/ou do sistema educativo), e como promotor de mudanças que possam contribuir para a melhoria dos processos e práticas de ensino e aprendizagem, e consequentemente para o sucesso educativo dos alunos (FLORES; FLORES, 1998).

\section{A FORMAÇÃO DOCENTE EM GRUPOS COLABORATIVOS}

A formação continuada nos grupos colaborativos tem se configurado como trabalho fecundo no desenvolvimento profissional de professores. Para Pacheco e Flores (1999, p. 135), num grupo colaborativo, "a formação contínua deve potencializar a colaboração dos diversos atores do sistema educativo e a realização de projetos de investigação-ação-formação orientados para o desenvolvimento profissional do professor". Nesses grupos, é necessário eleger o interesse comum entre os participantes, buscando avançar na compreensão do objeto que se pretende estudar. No trabalho com o GEProMAl, esta se constitui em opção primeira: buscar os interesses comuns dos participantes, qual seja, o da pesquisa e da compreensão da prática pedagógica, no que tange ao trabalho com a matemática - conteúdos e maneiras de ensinar - na infância.

Com a configuração do grupo e a eleição dos temas a serem estudados, a colaboração começa a ser constituída, encontro a encontro, tornando-se, mesmo, possível desenvolver investigações sobre diferentes temas e práticas. A prática da pesquisa colaborativa entre professores acadêmicos e professores escolares tem sido muito utilizada. Para Gama e Fiorentini (2009, p. 10),

Apesar da divisão histórica entre acadêmicos e práticos, que trabalham em culturas e/ou comunidades de prática distintas e respondem a exigências diferentes, nas últimas décadas têm-se buscado, nas parcerias colaborativas, os aprendizados mútuos e a superação dessa distinção.

Revelam ainda esses autores que tais parcerias auxiliam tanto na formação continuada como na inicial e tornam possível que, através de recursos congregadores, os participantes venham a "construir e proporcionar a produção de conhecimento que demanda práticas com posturas de reflexão e investigação" (GAMA; FIORENTINI, 2009, p. 13). 
Um dos objetivos, ao formar-se um grupo colaborativo de profissionais da educação, é a construção de conhecimentos que contribuam para transformar de maneira positiva a prática docente. É importante ressaltar que todo sujeito partícipe de um grupo colaborativo tem oportunidades iguais de se colocar, sugerir temas para estudo, propor ações de investigação, emitir opiniões, visto que uma das características essenciais de um grupo colaborativo é a prática da democracia. Na cultura de colaboração, Hargreaves (2001) salienta que as relações de trabalho entre os docentes tendem a ser espontâneas e voluntárias; são orientadas para o desenvolvimento; possibilitam que os professores trabalhem em conjunto, e são articuladas à vida profissional dos participantes.

$\mathrm{Na}$ investigação realizada, os grupos de estudos colaborativos são assumidos como contextos formativos que potencializam a aprendizagem docente, e a colaboração é compreendida na perspectiva apresentada por Fiorentini (2004, p.52):

$\mathrm{Na}$ colaboração, todos trabalham conjuntamente (colaboram) e se apoiam mutuamente, visando atingir objetivos comuns negociados pelo coletivo do grupo. Na colaboração, as relações, portanto, tendem a ser não hierárquicas, havendo liderança compartilhada e corresponsabilidade pela condução das ações.

Outra característica comum entre os grupos que congregam professores que ensinam Matemática na Educação Básica e acadêmicos (professores universitários, mestrandos e doutorandos), é a heterogeneidade (FIORENTINI, 2013). Nesses contextos, os professores da escola manifestam interesse em estudar, refletir e investigar sobre o ensino nessa etapa educacional, e buscar compreensões sobre as práticas desenvolvidas com os estudantes. Já os acadêmicos têm como objetivo investigar a formação contínua, a aprendizagem e o desenvolvimento profissional de professores em um contexto colaborativo.

Para Fiorentini (2013, p. 68-69), essa heterogeneidade é vista como um elemento que agrega qualidade ao grupo, pois:

[...]. Os professores da escola básica, por exemplo, trazem como excedente de visão, em relação aos formadores e futuros professores, um saber de experiência relativo ao ensino da Matemática nas escolas e conhecem as condições e as possibilidades de determinadas tarefas e práticas letivas. [...] Os formadores da universidade, por sua vez, têm como excedente de visão as teorias e metodologias a partir das quais produzem análises, interpretações e compreensões das práticas escolares vigentes, com o propósito de problematizá-las e desnaturalizá-las.

Posturas colaborativas requerem o abandono do individualismo e das práticas privatizadas e a abertura à discussão, à crítica e à construção coletiva. O ambiente colaborativo do GEProMAI possui tais características: discute a escola e suas condições, mas estimula a superação de tais obstáculos. Como ferramenta importante, somos envolvidos na escrita de narrativas.

\subsection{Educação matemática na infância: um olhar para grandezas e medidas}

Entendemos a criança como sujeito da aprendizagem e julgamos que a educação intencionalmente planejada pode ampliar e enriquecer as oportunidades para que ela aprenda e se desenvolva. Dessa maneira, o trabalho com a Matemática desde a Educação Infantil configurase como ação importante, pois, ao admiti-la como um produto cultural, é possível oportunizar às crianças experiências com o universo matemático que lhes possibilitem descobrir; tecer relações; organizar o pensamento; interagir com o meio, com crianças e adultos; compartilhar interesses, necessidades e conhecimentos (FERREIRA, 2015).

Um aspecto importante da Educação Matemática para a infância destacado por Lopes (2012) é a necessidade do respeito à cultura e aos saberes infantis adquiridos no meio cultural onde a criança vive; e nessa perspectiva o tema Grandezas e Medidas adquire relevância, pois está presente no cotidiano. Também é fundamental que nessa etapa educacional sejam propostas situações sobre as quais as crianças possam refletir, emitir opiniões, levantar possibilidades e investigar. A resolução de problemas se configura, então, como um modo fértil de propiciar diferentes aprendizagens. Nessa mesma perspectiva, Lopes e Grando (2012), enfatizam que a Matemática precisa ser trabalhada de 
forma integrada aos projetos e às ações desenvolvidas na educação da infância, em situações nas quais as crianças estejam resolvendo problemas, jogando e brincando.

Portanto, é relevante enfatizar que não entendemos a Educação Matemática na infância centrada em algoritmos, regras, convenções, atividades mecânicas, memorizações, repetições, etc. (LOPES, 2012). No processo de educar-se matematicamente, é necessário propor situações nas quais a criança possa pensar, questionar, estabelecer relações, descobrir, expressar dúvidas e comunicar suas ideias e hipóteses. Nessa interação, a professora não apenas desenvolve concepções mais elaboradas de como se processa o pensamento matemático, mas também constrói estratégias para lidar com os conceitos ou noções que quer ensinar-Ihes (SERRAZINA, 2014).

Compreendemos como fundamental que as práticas docentes propostas pelos professores no âmbito das grandezas e medidas sejam planejadas intencionalmente e provoquem "experiências de novo tipo, para favorecer o domínio de novos procedimentos na atividade e para a formação de novos processos psíquicos" (MELLO, 2007, p. 94).

É comum observar que as crianças, ao brincar, medem distâncias, espaços e objetos, estimam tempo, verificam se um líquido está quente ou gelado, se um objeto é leve ou pesado, ou ainda se é grande, médio ou pequeno. A atitude de medir nos acompanha durante toda a vida, configurandose em ações diárias. Assim, Caraça (1963, p. 29) afirma que "toda gente, nas mais variadas circunstâncias, qualquer que seja sua profissão, tem a necessidade de medir".

Considerando a presença e a importância da medida na vida cotidiana, Moura (1995) evidencia que a medida aparece a partir das demandas de controle de variações das dimensões dos objetos, especialmente em construções, deslocamentos, culinária, produções artísticas, leituras de gráficos e tabelas, entre outras situações em que a medida e o ato de medir surgem, impregnados de significados culturais advindos das relações humanas que representam e comunicam. Para Ponte e Serrazina (2000) para que as crianças compreendam o processo de medição é fundamental que elas realizem experiências concretas, como por exemplo, utilizar diferentes unidades de medida em diversas situações possibilita perceber a necessidade de uma unidade de medida padrão e concluir que o número de unidades necessárias depende da unidade de medida utilizada.

De acordo com Caraça (1963, p. 29), "medir consiste em comparar duas grandezas da mesma espécie - dois comprimentos, dois pesos, dois volumes, etc.". Destacando os procedimentos necessários à realização da medição, Caraça (1963) salienta que é preciso estabelecer um padrão único de comparação para todas as grandezas de mesma espécie. Esse padrão chama-se unidade de medida da grandeza com a qual se está tratando. Além disso, é preciso responder à questão "quantas vezes?", o que se faz atribuindo um número que expresse o resultado da comparação com a unidade. Esse número chama-se a medida da grandeza com relação à unidade. $\mathrm{O}$ autor salienta que, no problema de medir, é possível considerar três fases e três aspectos distintos: a escolha da unidade, a comparação com a unidade e a expressão numérica do resultado dessa comparação. Para ele, existe uma interdependência entre esses três aspectos, sendo que o primeiro e o terceiro estão intimamente ligados e um condiciona o outro, estabelecendo-se assim uma relação dialética.

\subsection{Aspectos teóricos: medidas de comprimento}

Clements e Stephan (2004), tomando por base a ideia de medir comprimentos (uma dimensão), apresentam seis princípios que sustentam a compreensão da atividade matemática de medir unidimensionalmente: partição do objeto; unidade de iteração; transitividade; conservação; acumulação da distância; e relação com um valor numérico.

A partição envolve a atividade mental de dividir o objeto em unidades menores e de mesmo comprimento - considerando o caso particular de a unidade ser menor que o objeto a medir. A unidade de iteração refere-se à habilidade de pensar num comprimento como referência para 'cobrir' todo o comprimento do objeto a ser medido, num processo que garante que as extremidades final e inicial dessa referência coincidam, sem que se deixem espaços entre duas unidades subsequentes ou que se sobreponham unidades adjacentes. A transitividade se configura como processo de obtenção, por meio de estimativa ou dedução, de uma relação de igualdade ou desigualdade (superior ou inferior) de uma grandeza e de ampliação para outros dois ou mais objetos (MESTRINHO; OLIVEIRA, 2012), ou seja, quando se elege um terceiro objeto para comparar a medida de outros dois. A conservação de comprimento relaciona-se com a noção de que, se um objeto é movido, seu comprimento não se altera. O comprimento se conserva independentemente da posição do objeto. A acumulação de 
distância é o entendimento de que, enquanto você itera para a unidade ao longo do comprimento de um objeto e conta a iteração, as palavras numéricas significam o espaço coberto por todas as unidades, contado até esse ponto. A relação da medida com um valor numérico vincula-se à necessidade de as crianças precisarem reorganizar sua compreensão da contagem de objetos discretos para o tipo de contagem de distância/comprimento, ao medir unidades contínuas.

Caraça (1963) afirma que, ao escolher a unidade de medida, é importante que seja considerada sua praticidade, comodidade e economia. Pode-se escolher a unidade como quiser, mas, na prática, o número que resulta da medição está condicionado à escolha da unidade. Como exemplo de seleção da unidade, o autor afirma que "seria tão incômodo tomar como unidade de comprimento de tecidos para vestuário a légua3, como tomar para unidade de distância geográfica o milímetro" (CARAÇA, 1963, p. 31).

Portanto, é fundamental refletir sobre a unidade de medida que acompanha um número, o indicador da quantidade, pois apenas o número é insuficiente para representar a grandeza. A discussão sobre a relação entre número e unidade de medida é essencial. Por exemplo, o número 300 , apesar de representar maior quantidade que o número 30 (em termos de contagem de objetos) representa uma menor quantidade de produto se compararmos 300 centímetros de barbante com 30 metros do mesmo material. Dessa forma, a unidade de medida compõe a quantidade juntamente com o número.

Outro aspecto importante a ser destacado no ato de medir refere-se ao fato de que, no processo de medição de um objeto, são necessários dois tipos de operação: uma de caráter geométrico, que aplica a unidade ao longo da grandeza a ser medida, e outra de caráter aritmético, que calcula quantas vezes é possível repetir a operação anterior. Desse modo, fica evidente "a existência de uma estreita relação entre ambas, o que produz uma nova operação: medir" (MOURA, 1995, p. 47).

\subsection{Aspectos teóricos: medidas de tempo}

A grandeza tempo também se configura como um aspecto a ser trabalhado no tema medidas. Salienta-se que o conceito de tempo é bastante complexo para as crianças. Suas experiências concentram-se no presente, sendo difícil para elas conceituar ideias como passado e futuro (INHELDER; PIAGET, 2003). Para León (2011), o conceito de tempo resulta de uma construção individual que afeta significativamente todas as áreas do desenvolvimento do ser humano, sendo percebido e processado a partir de diferentes perspectivas, dependendo da natureza e do impacto das experiências vivenciadas e do contexto cultural e social em que cada pessoa se desenvolve.

Diferentemente das medidas espaciais, que envolvem a comparação entre dois objetos, o que se mede e o instrumento de medida, a medição do tempo envolve relações de outra natureza e compreensões a respeito de algo subjetivo. No entanto, a medida de tempo é realizada por meio da comparação, pois um evento pode durar mais ou menos que outro. A medida da duração do evento será dada por "quantas vezes" a unidade T (segundo, minuto, hora,...) ocorre no decorrer do evento.

Além disso, a medição do tempo apresenta relação com os princípios observados em outras grandezas, como os apresentados por Clements e Stephan (2004): a partição, uma hora pode ser divida em 60 minutos; a transitividade, é possível estimar um horário ou intervalo de tempo a partir de diferentes estratégias; a conservação do intervalo, embora não seja perceptível fisicamente, a duração de um intervalo não se altera. Assim como na medição do comprimento, a relação da medida com um valor numérico pressupõe a necessidade de reorganização da compreensão da contagem de objetos discretos para um tipo de contagem que envolve medir unidades contínuas por meio de instrumentos de medida. Também utiliza-se de pontos de referência e do encadeamento de várias relações, como o dia e a noite; manhã, tarde e noite; dias da semana; os meses do ano; presente, passado e futuro; antes, agora e depois, entre outras noções que contribuem para a estruturação do pensamento a respeito do tempo (BRASIL,1998).

Para Godino, Batanero e Roa (2002), as crianças não compreendem o tempo e seu ritmo, até chegarem aos níveis superiores da Educação Básica. E mesmo nessa etapa algumas revelam fraca compreensão da passagem do tempo e quase nenhuma concepção de tempo histórico, o que faz a percepção do tempo configurar-se em um atributo mensurável, que progride ao longo dos anos escolares. Para os autores, é fundamental utilizar as diferentes oportunidades para desenvolver a

Légua: Légua era a denominação de várias unidades de medidas de itinerários (de comprimentos longos) utilizadas em Portugal, no Brasil e em outros países, até à introdução do sistema métrico. As várias unidades com esta denominação tinham valores que variavam entre os atuais 2 a 7 quilômetros. Informação disponível em: https://pt.wikipedia.org/wiki/Légua. Acesso em: 01 nov. 2017. 
ideia de tempo e descritores para marcar a passagem do tempo, comparar e estimar os intervalos e a medição com diferentes instrumentos.

As observações sobre as operações envolvidas no processo de medir e a forte relação deste tema com diferentes conceitos matemáticos e com outras áreas do conhecimento enfatizam a relevância do trabalho com Grandezas e Medidas a partir de vivências, experiências, explorações, brincadeiras e jogos desde a Educação Infantil, para possibilitar que a criança construa intuitivamente noções matemáticas importantes.

Ao estudar o trabalho com a Matemática na Educação Infantil, Lorenzato (2006) enfatiza que o conceito de medida é abrangente e complexo. E salienta que o campo conceitual da medida é composto de aspectos relacionados às grandezas e ao vocabulário; aos objetos e suas características; às unidades de medida; aos quantificadores e à Matemática.

As crianças pequenas, a partir de experiências do seu meio cultural, conseguem identificar alguns instrumentos de medida, como régua, trena, balança, e relatar aspectos de sua utilização, considerando sua própria vivência: o uso da balança para se pesar em situações de consultas médicas; a utilização de uma fita métrica pela costureira; o uso de uma trena por um pedreiro. $\mathrm{O}$ fato de terem algum conhecimento sobre esses instrumentos não significa que as crianças compreendam as unidades de medida marcadas por eles e tampouco que elas adquiram esse conhecimento na Educação Infantil. Nesse sentido, como afirma Moura (1995), é essencial que, nas instituições educacionais, as atividades propostas não reduzam as ações das crianças ao que elas já conhecem, mas que lhes sejam oportunizadas vivências que solicitem a reelaboração do nível em que estão para um mais elaborado.

\section{CONTEXTO E MÉTODO DA PESQUISA}

A pesquisa foi desenvolvida, tendo como contexto GEProMAl, constituído há três anos, com participação de 12 professores e pesquisadores - que atuam na Educação Infantil, nos anos iniciais do Ensino Fundamental, desenvolvem pesquisas de mestrado e doutorado em Educação - e de docentes da universidade. Os encontros ocorrem quinzenalmente no espaço de uma universidade privada de Campinas.

O grupo possui como práticas: o estudo de textos teóricos e documentos curriculares, a produção de narrativas individuais nas situações que os participantes julgam necessárias, a elaboração de narrativas colaborativas de cada encontro, a produção colaborativa de textos para participação em eventos, a exploração de materiais didático-pedagógicos para ensinar, a produção individual e colaborativa de práticas para as diferentes turmas de Educação Infantil e Anos Iniciais do Ensino Fundamental; e a produção de narrativas sobre práticas desenvolvidas em sala de aula numa perspectiva investigativa.

O GEProMAI possui características colaborativas, pois a participação de todos é voluntária, os temas de estudos são selecionados a partir do interesse comum, as relações são horizontais e não hierárquicas e o cronograma é estabelecido pelo próprio grupo (HARGREAVES, 2001; FIORENTINI, 2004).

A perspectiva da colaboração é destacada pelos professores do GEProMAl, quando comentam sobre a própria participação:

[...] a importância e o diferencial do GRUPO são evidentes, já que ele se constitui a partir de dinâmicas de colaboração entre todos os envolvidos para definição de temas de estudo, do formato das reuniões, da flexibilidade em compartilhar experiências profissionais e pessoais que ocorre num ambiente de muito respeito onde todos são ouvidos e sentem liberdade para expor suas fragilidades geradas por uma formação que não dá conta de abarcar todos os conteúdos de tantas disciplinas envolvidas na função de um professor polivalente. A partir das discussões e ações realizadas ao longo dos encontros, tem-se constituído o GRUPO, que se pauta em quatro elementos fundamentais: o foco no ensino e aprendizagem da Matemática; a organização do grupo colaborativo; a discussão das práticas pedagógicas; e a escrita de narrativas (ALMEIDA et al., 2014).

A metodologia de pesquisa está ancorada na "pesquisa narrativa como uma forma de compreender a experiência” (CLANDININ; CONELLY, 2011, p. 51). Desse modo, buscou-se 
compreender as experiências vivenciadas pelas autoras na interlocução com os participantes do grupo.

Os instrumentos de pesquisa, denominados aqui "textos de campo", compreendem narrativas orais captadas em videogravações dos encontros do grupo; narrativas individuais sobre os encontros, elaboradas pelos componentes do grupo; narrativas colaborativas ${ }^{4}$ sobre os encontros, produzidas pelos participantes em ambiente virtual (Google Docs), textos produzidos pelos integrantes do grupo para participação em eventos e/ou para publicação e notas de campo das pesquisadoras.

Considerando as experiências formativas desenvolvidas no grupo relacionadas a ações que envolveram medidas, trazemos aqui episódios que evidenciam as reverberações das mesmas nas práticas de dois professores. Cabe salientar que o tema global da pesquisa foi relacionado a medidas. Na primeira parte da análise discutimos a medida de distancia/comprimento, com foco no trabalho da professora KR com uma turma de Educação Infantil. Em seguida discutimos a medida de tempo a partir do trabalho do professor $D N$ em um $3^{\circ}$ ano do Ensino Fundamental.

Para favorecer a compreensão das análises, detalhamos a seguir aspectos das situações no grupo que propiciaram o estudo da medida de distância/comprimento e da medida de tempo.

\subsection{Contexto GEProMAI - Medida de Comprimento/Distância e Medida de Tempo}

Para iniciar os estudos a respeito das medidas de comprimento, os participantes do GEProMAI estudaram o texto "O medir de crianças pré-escolares" (MOURA; LORENZATO, 2001), que aborda aspectos conceituais da medida e práticas desenvolvidas com crianças na instituição escolar a partir da resolução de diferentes problemas. Também foi estudado o artigo "Dois pesos e duas medidas: uma proposta para discutir a natureza do sistema de unidades de medida na sala de aula" (GODOI; FIGUEIROA, 2008), que discute aspectos históricos do sistema de unidades de medida adotado atualmente (SI), enfatizando sua construção como um processo histórico de negociação de significados.

Dentre as situações estudadas, a prática desenvolvida a partir da história do Curupira apresentada no primeiro texto chamou atenção do grupo, em especial da Professora $K R$, que trabalhava, à época, com crianças de Educação Infantil de idades entre 3 e 6 anos. A história apresenta um problema como foco central para a reflexão sobre as unidades de medida de comprimento, propondo às crianças ações de medir. Apresenta a seguinte situação: o Curupira encontrou na floresta um anão e um gigante e os convidou para jantar em sua casa, indicando que ela ficava a 30 passos do lugar onde estavam. No horário marcado, os dois amigos deram os 30 passos na direção indicada pelo Curupira, porém não conseguiram chegar à sua casa. O que teria ocorrido? (MEGID; ALMEIDA, 2017). A proposta era a de que a história mobilizasse as crianças a discutir por que isso havia acontecido e a buscar meios para resolver este problema.

A partir das discussões no grupo, KR planejou e desenvolveu um trabalho com sua turma, utilizando uma versão dessa história. Refletindo sobre o que ocorreu em sua sala, produziu uma narrativa a respeito dessa prática, compartilhando-a com o grupo.

Eu fui escrevendo o que fui fazendo e retomando o texto que a gente leu. Procurei também aquele livro do Sérgio Lorenzato (referindo-se à obra de Lorenzato, 2006, Educação Infantil e Percepção Matemática), quando ele fala também um pouco sobre medidas. Posso ler?

A professora elaborou uma narrativa escrita de sua prática, além de documentá-la por meio de fotos e desenhos feitos pelas crianças, com o intuito de favorecer a compreensão do grupo sobre como as atividades tinham sido desenvolvidas na escola. Essa atitude demonstra uma preocupação em fazer-se compreender pelas(os) colegas e também em possibilitar um diálogo efetivo sobre o trabalho realizado, tornando o tempo de encontro do grupo o mais produtivo possível (FIORENTINI, 2004).

Ao finalizar o relato sobre seis dias de atividades com as suas crianças, $K R$ nos mostrou os desenhos que elas produziram sobre a lenda do Curupira, nos apresentou fotografias delas realizando as atividades, e, na sequência, questionou e avaliou sua prática até então. Ela nos trouxe sua percepção de que as atividades realizadas foram muito boas e propiciaram aprendizagens para grande parte das crianças. No entanto, observou que as mais novas, com exceção de um dos dias,

\footnotetext{
4 Maiores detalhes sobre narrativas colaborativas podem ser encontradas em: https://www.revistas.ufg.br/interacao/article/view/41858/23213
} 
ficaram mais tempo como espectadoras e tiveram pouco protagonismo no desenvolvimento das atividades realizadas durante a semana. Diante disso, afirmou ainda que iria rever o plano que já havia organizado para a semana seguinte e propor atividades que abordassem o mesmo tema, mas que considerava serem mais inclusivas, para acolher as crianças menores.

Tendo ainda como tema central de nossos estudos as Grandezas e Medidas, em outro encontro, optamos por conversar a respeito da medida de tempo, a partir das discussões a respeito do Caderno 6 - "Grandezas e Medidas" - do Pacto Nacional pela Alfabetização na Idade Certa PNAIC - (BRASIL, 2014). Tal estudo mobilizou uma discussão a respeito do trabalho com medidas de tempo com as crianças, ação que se configura como um desafio, pois se trata, como anteriormente indicado, de um conceito abstrato e intangível para muitas delas.

Discutimos que a ideia de tempo está relacionada a diferentes perspectivas, entre elas a Física, a História, a Psicologia e a Matemática, e um dos modos de considerar o tempo matematicamente pode ser relacionado à medida de intervalos de tempo. Como exemplo, marcar a duração de tempo de dois eventos que iniciam ao mesmo tempo, sendo aquele que termina depois o que se configura com maior tempo. Além disso, envolve a utilização de instrumento de medidas, como relógios, cronômetros e ampulhetas, para medir o intervalo de tempo de um acontecimento. Conversamos ainda a respeito da subjetividade da medida de tempo: o que é mais prazeroso passa mais rápido, o que é enfadonho, demora mais.

Considerando essas discussões, um dos professores, $D N$, compartilhou com o grupo uma prática que desenvolveu com suas crianças de $3 .^{\circ}$ ano naquela mesma semana. Afirmou considerar ser este um tema muito complexo para abordar com crianças:

[...] é muito difícil trabalhar a ideia de tempo com as crianças, porque é muito abstrato. Não é algo que você enxerga e pega. Se você vai medir o comprimento, você consegue mostrar algo e dizer: isso é um metro. Também pode dizer: isso é um quilo, apresentando um pacote de açúcar. Mas o tempo não tem um comparativo real, você não "pega" a hora, você estima, o que traz um aspecto muito subjetivo.[...]. Mesmo que se pense no intervalo de tempo, ainda assim fica subjetivo

Na proposta, $D N$ solicitou às crianças que estimassem o tempo de diferentes momentos que ocorrem na escola. Pediu que registrassem os tempos de duração relativos a estas atividades: a acolhida que acontece todos os dias, a leitura, a escovação dos dentes, o momento da alimentação e recreio, a aula de Artes que teriam naquele dia e outros momentos da rotina escolar. Cada aluno elaborou uma tabela contendo as atividades e o tempo que estimava usar para cada uma, sem utilizar qualquer instrumento de medida.

O objetivo da tarefa foi o de verificar se as crianças conseguiriam estabelecer uma relação entre a duração de tempo das diferentes atividades e o número de horas que permaneciam na escola, com o intuito de discutir relações entre fatos e ações, envolvendo noções temporais.

Estimar uma medida de tempo, no caso deste estudo refere-se ao processo de determinação de uma medida aproximada, informações mentais e visuais, e sem a utilização de instrumentos de medição e / ou sem fazer uma medida exata (SUBRAMANIAM, 2014). As estimativas são muito frequentes e úteis nas atividades cotidianas, o que justifica a importância de desenvolver esta habilidade na escola. Além disso, as atividades que envolvem a estimativa das medidas devem ser consideradas como um dos componentes do processo de medir, pois auxiliam os alunos a compreender os diferentes aspectos que entram em jogo (GODINO; BATANERO; ROA, 2002).

\subsection{Aprendizagens sobre medidas de comprimento na Educação Infantil}

Ao iniciar sua narrativa sobre o trabalho com medidas de comprimento/distância e remeter-se aos seus escritos, KR inicia um processo de análise de sua prática (PONTE, 2004), pois procura compreendê-la na interlocução com um dos textos estudados no grupo e com outro que buscou, por iniciativa própria, reconhecendo que os aportes teóricos e as discussões no grupo contribuíram para a compreensão e a interpretação da prática de ensinar e aprender Matemática com sua turma.

$\mathrm{KR}$ comenta no grupo que inicialmente ficou apreensiva com a realização da proposta com medidas: 
Pensei que seria um tema difícil para crianças pequenas. Porém, através da leitura do texto "O Medir de Crianças Pré-Escolares" e dos diálogos com o grupo no encontro anterior, fiquei entusiasmada e imaginando qual seria a reação das crianças.

Mesmo declarando certa insegurança inicial, $K R$ desenvolveu na escola diversas atividades relacionadas às medidas de comprimento e à história do Curupira durante seis encontros com os alunos. Nesse período, planejou diferentes propostas: contou a história do Curupira diariamente, conversou sobre as características dos personagens, realizou atividades com desenho e dramatização e buscou diversos modos de incentivar as crianças a pensar para resolver o problema. Instigava seus alunos a partir de questionamentos: "por que eles não conseguiram chegar à casa do Curupira? Como podemos ajudá-los a encontrá-la?".

Em seu texto narrativo, $K R$ apresenta algumas hipóteses das crianças sobre o porquê de nem o anão nem o gigante encontrarem a casa do Curupira: eles se perderam; foram pelo caminho errado; eles não tinham mapa; eles precisariam de um telescópio, entre outras. Embora percebendo como importantes e criativas as hipóteses das crianças, a professora optou por aprofundar-se nas discussões sobre o problema apresentado. Isso levou-a a questionar-se sobre quais outras propostas poderiam ser desenvolvidas com as crianças, a fim de que pensassem sobre as medidas para resolvê-lo.

Ao refletir sobre sua prática, $K R$ salientou que teve a impressão de que no texto de Moura e Lorenzato (2001) as crianças falam a respeito da contagem dos 30 passos já num primeiro momento, e se questionou por que com sua turma foi diferente. Observou que, no artigo lido, a atividade foi realizada com crianças de 6 anos. Já, em sua turma, a maior parte das crianças tinha entre 4 e 5 anos, o que exigiu a ampliação e a adaptação de atividades e estratégias didáticas para atingir o mesmo objetivo, qual seja, o de identificar a quantidade de passos necessários para se chegar à casa do Curupira, reconhecendo a necessidade da expressão numérica resultante da medição. Esse comentário demonstra novamente a interlocução da professora com os estudos e também com os participantes no grupo, além de uma preocupação em ter a teoria como um meio de problematizar, compreender e transformar sua prática docente (FIORENTINI; CARVALHO, 2015).

Após o progresso em relação à contagem dos 30 passos, outro momento marcante dessa prática foi quando as crianças perceberam a diferença no comprimento dos passos dos três personagens: Curupira, Anão e Gigante.

[...] e então meu aluno teve essa grande ideia: "Por que não pegamos três crianças, uma para
ser o anão, outra o gigante e outra o Curupira?" Essa criança que deu a ideia já se levantou
e disse: "Eu sou o gigante". Uma outra colega apontou para outro menino e falou: "Você é
o anão! Abaixa!" O menininho levantou e ela repetiu: "Abaixa! (risos) - pra ficar menor". Na
sequência, outra criança fala: "Agora é só dar 30 passos. O passo do gigante tem que ser
assim". Ele mostrou como deveria ser o passo do gigante, e afastou os pés o máximo que
conseguia.

$K R$ relatou que uma das crianças propôs um modo de solucionar o problema a partir de uma dramatização e que elas próprias tiveram a iniciativa de desenvolvê-la com o apoio da professora. Compreendemos no grupo que as crianças evocaram a relação entre os tamanhos dos passos dos personagens, mas estimuladas pela gestão que $K R$ fez de sua aula. Embora a professora tivesse um plano para o trabalho daquele dia, após uma sugestão apresentada por uma criança, a qual estava totalmente de acordo com o tema matemático a ser trabalhado, ela alterou sua proposta e desenvolveu a dramatização, considerando as indicações das crianças. Desse modo, $K R$ escutou as crianças e valorizou as estratégias delas para a solução do problema (SERRAZINA, 2014).

Todos os participantes da reunião concordamos que vimos na prática de $K R$ uma gestão de sala de aula que, ao ouvir as crianças, propor questionamentos, incentivar a resolução de problemas, aguardar o tempo necessário para que elas pudessem pensar e propor soluções, alterar o plano em decorrência de uma proposta de atividade de uma criança, entre outras ações, auxiliou na construção de conceitos e, por conseguinte, na aprendizagem. Assim, a professora, como mediadora, configurase naquela pessoa que tem um excedente de visão, conforme destaca Bakhtin (2003), trazendo uma nova informação, uma nova proposta, o que é muito importante para que as crianças aprendam. 
As ponderações de $K R$ permitem observar que a professora questionou sua prática diante do grupo e suscitou novas conversas sobre estratégias para envolver seus alunos nas atividades, com o intuito de promover oportunidades de aprendizagem para todos. Com base em Mello (2007), é possível considerar que $K R$, ao se questionar e ao criticar sua própria prática, se coloca como uma professora da infância que tem como compromisso satisfazer as necessidades de conhecimento e de atividade da criança, "procurando despertar nela novos interesses e ensinando-lhe novos modos de agir, e reconhece o seu papel mediador e a atitude ativa da criança em todos os momentos da rotina diária da instituição educativa" (MELLO, 2007, p. 26).

Os comentários de KR revelam que o GRUPO se configurou como um espaço de apoio para enfrentar o desafio de propor uma prática no âmbito das medidas, diferente das que estava acostumada (FIORENTINI, 2004).

[...] as discussões e reflexões reforçaram a ideia de que é fundamental propiciar maior espaço para a investigação, manipulação, construção coletiva e o diálogo. E tudo isso se faz "vivo" e mais consistente em minha formação, porque no GEProMAI vivenciei este processo, em que a fala, as ideias, o lúdico e a troca são valorizados. $E$ isso faz muita diferença. Ter a oportunidade de experimentar o prazer em compreender e atribuir significado, deveria ser um direito, principalmente àqueles que escolheram a docência como profissão. Agora, um "incômodo agradável" me persegue... Como garantir às crianças momentos significativos de aprendizagem? (excerto da narrativa de KR)

É importante evidenciar ainda que KR compartilhou com uma professora da escola - que não participava do GEProMAI, mas trabalhava com crianças da mesma faixa etária - seus planos, as práticas e o envolvimento das crianças nas atividades, o que inspirou essa professora a também propor o tema Medidas com sua turma. O desenvolvimento das atividades das duas docentes em parceria culminou na produção de um texto reflexivo sobre as práticas e as aprendizagens das crianças e foi apresentado em um evento no ano 2014: "Passo do curupira? Trabalhando medidas na educação infantil" (FERNANDES; PAULINO, 2014).

Para $K R$, o estudo sobre medidas no grupo colaborativo se configurou como uma oportunidade de mudança nas práticas, ao trabalhar Grandezas e Medidas com as crianças. Tal reverberação se deu por meio do trabalho com a lenda do Curupira, uma proposta diferente das realizadas sobre 0 tema:

Minhas tentativas de trabalho com medidas, até então, restringiam-se em medir as crianças com barbante, depois com fita métrica, compará-los e expor as medidas de cada um" (narrativa individual de KR, enviada por e-mail em 12 set. 2014).

As reverberações dos estudos em grupo nas práticas da professora ocorreram por meio das atividades realizadas na escola em que atua. A interlocução com os participantes do grupo e com textos estudados se fez presente, não como uma reprodução literal do que foi estudado e discutido, uma replicação direta de outras experiências, mas como uma elaboração própria da professora, considerando suas aprendizagens pessoais e o contexto educacional em que atua.

\subsection{Aprendizagens sobre medida de tempo no Ensino Fundamental}

Para conhecer as estimativas realizadas, DN elaborou uma planilha com os dados produzidos pelos alunos. Em sua análise observou que alguns chegaram perto da realidade de 5 horas, espaço-tempo em que ficam diariamente na escola. Entretanto, outros realizaram estimativas muito distantes do tempo real, indicando que a duração de uma aula de Artes seria de 4 horas, a leitura de um texto, 2 horas; e estimando que as demais atividades somaram 10, 12 e 20 horas para serem realizadas. O professor revelou-se surpreso, ao analisar os registros dos alunos, embora soubesse que a comparação de intervalos de tempo é difícil até mesmo para os adultos. Tal análise confirmou o encontrado em Godino, Batanero e Roa (2002) a respeito da incompreensão do tempo e de seu ritmo nos anos iniciais de escolarização.

DN comentou que, ao perguntar às crianças sobre qual era o horário de entrada e saída da escola, elas responderam que entravam às sete e saíam ao meio-dia. Também sabiam que esse 
intervalo de tempo era de cinco horas. No entanto, muitos não estabeleceram relação entre esse período conhecido, de cinco horas na escola, com os intervalos de tempo das diferentes atividades.

O professor indicou, na reunião do GEProMAI, que gostaria de problematizar essa situação com as crianças e solicitou novas contribuições para realizar o trabalho. Provocou uma discussão relacionada à possibilidade de ele mostrar para a turma três exemplos de respostas registradas pelos alunos, sem colocar o valor real de tempo utilizado nos diferentes momentos da rotina escolar. Foi proposto ainda que não apresentasse o total de horas do período escolar. Ele foi também instigado pelos outros participantes do grupo a fazer alguns questionamentos às crianças: quanto tempo será que dura a aula de artes? Será que passamos tanto tempo no recreio? E as demais aulas, quanto tempo duram? O que sabemos sobre a duração de um dia inteiro?

As sugestões foram colocadas na perspectiva de propor outras questões a respeito do tempo para os alunos pensarem, buscando estabelecer relações entre os acontecimentos da vida diária e a ampliação das noções temporais. Ainda foi sugerida a confecção e a utilização de ampulhetas que auxiliariam na medição do tempo e ofereceriam a exposição de diferentes maneiras de se medir o tempo ao longo da história. Tais propostas foram utilizadas pelo professor e discutidas posteriormente com o grupo.

No encontro seguinte, DN relatou as práticas realizadas na escola. Trouxe, além da perspectiva matemática, a ideia psicológica de tempo, da subjetividade que a envolve. Essa interlocução possibilitou um debate amplo do tema, que, tendo emergido dos estudos e do contexto da escola, possibilita a reflexão sobre o tempo, considerando diferentes perspectivas.

Ao discutir no grupo sua prática, DN despertou a colaboração rápida de outros professores envolvidos no processo de melhorar o ensino e a aprendizagem da Matemática. Mais uma vez constatamos que tal situação reverbera na prática do professor, quando ele retoma as novas problematizações sobre o tempo na escola. Portanto, é possível considerar que tanto DN quanto os demais participantes do GEProMAI aprenderam por meio da reflexão em grupo e trabalharam em conjunto, questionando seus próprios pressupostos e expondo problemas de prática que requerem que estudem seus próprios alunos e escolas (COCHRAN-SMITH, 2012).

Ao desenvolver as práticas a respeito das estimativas de medidas de tempo e problematizar com os alunos suas compreensões relacionadas a esse conceito, o professor percebeu-o como aspecto denso e complexo e concluiu que o ensino e a aprendizagem relacionados às medidas de tempo configuram-se em um processo que deve estar presente permanentemente nas aulas ao longo do ano letivo.

\section{CONSIDERAÇÕES FINAIS}

A participação no grupo de estudos com a abordagem de discutir textos teóricos e materiais de orientação curricular, de preparar conjuntamente, discutir, implementar atividades, refletir e escrever sobre essas práticas no e com o grupo, possibilitou aos docentes aprendizagens conceituais sobre as grandezas e medidas e sobre seu ensino e aprendizagem. As ações reverberaram em suas práticas por meio da inserção do tema e/ou de alterações graduais nas maneiras de abordá-lo com crianças, utilizando ações mais exploratórias e problematizadoras.

As práticas a respeito das medidas de comprimento e de tempo compartilhadas no grupo levaram em consideração aspectos sociais e culturais de seu uso (MOURA, 1995), possibilitando a apropriação de um instrumento intelectual importante para a compreensão da realidade e para o desenvolvimento de aprendizagens futuras.

O GEProMAI se constituiu como um contexto de estudos e apoio às mudanças na prática docente. Nos encontros os professores aprenderam aspectos implicados no processo de medição como a comparação, a necessidade da iteração de modo correto, a importância de oferecer situações para que as crianças percebam a necessidade de unidades de medida padronizadas, seja com unidades standard como os minutos, no caso da medida de tempo, ou não standard como os passos, no caso da medida de comprimento/distância. Ainda discutiram a relação entre o número e a medida da grandeza e a necessidade de perceber a diferença entre o número natural utilizado para contagem de grandezas discretas e o número natural que expressa o resultado de uma comparação no processo de medição.

As reverberações dessas aprendizagens nas práticas dos professores $K R$ e $D N$ são observadas quando eles inseriram o trabalho com medidas em suas turmas após um estudo mais aprofundado 
sobre o tema. As atividades propostas foram desenvolvidas com o intuito de promover situações em que os alunos pudessem refletir, comparar, estimar e resolver problemas. As ações dos professores possibilitaram o rompimento com a dicotomia entre a teoria e a prática, pois a partir das discussões no grupo os docentes produziram conhecimentos sobre as práticas desenvolvidas ${ }^{5}$. Tais reverberações ajudaram na compreensão de conteúdos matemáticos e pedagógicos importantes para o professor que "ensina-aprende" Matemática nos anos iniciais de escolarização.

As reverberações também são percebidas quando os professores desnaturalizam algumas atitudes cotidianas do trabalho com as medidas, como por exemplo, propor uma atividade envolvendo estimativas de intervalos de tempo numa situação real do cotidiano escolar, ao invés de utilizar contextos artificiais propostos em livros didáticos ou apostilas. Ou ainda, ao desenvolver uma sequência de atividades que propiciem às crianças perceberem a necessidade de uma unidade padrão de medida (passo do Curupira) e da relação entre o número de passos e a distância a ser percorrida, ao invés de restringir o trabalho com comprimento à comparação da altura das crianças da turma.

A participação no grupo de estudos contribuiu para que os professores se sentissem seguros para promover novas práticas a respeito das Grandezas e Medidas com suas turmas. Especificamente no que se refere à professora $K R$ é possível afirmar que ela atuou como agente de mudança não apenas em sua sala de aula, mas na escola como um todo (COCHRAN-SMITH, 2012; SARAIVA; PONTE, 2003), pois expandiu o que aprendeu no GEProMAI para outros professores que não participam do grupo, possibilitando que eles também implementassem as práticas das medidas de comprimento/distância na escola com suas turmas. Isso também ocorreu quando ela produziu em parceria com outra professora um texto que detalhava a implementação da atividade nas duas turmas (FERNANDES; PAULINO, 2014). Nesse sentido destacamos que as discussões teóricas no grupo, situadas na prática do professor, permitiram que fossem atribuídos significados, possibilitando inclusive uma expansão dessas discussões relacionadas às práticas a outros professores que atuam em contexto educativo similar.

$\mathrm{Da}$ análise efetuada foi possível verificar que as atividades propostas pelos professores efetivamente abordaram as grandezas e medidas de maneira exploratória e investigativa, considerando as etapas escolares e o contexto em que se inseriam.

Os resultados desta investigação permitem afirmar que a elaboração conjunta de atividades a respeito das medidas de comprimento/distância e de tempo, acompanhadas da discussão e reflexão com os participantes do grupo, propiciaram uma compreensão a respeito da importância de o professor aprofundar seus conhecimentos sobre os conteúdos matemáticos e pedagógicos para ensinar na Educação Infantil e anos iniciais do Ensino Fundamental. Ainda, foram essenciais para que os docentes pesquisados inserissem mudanças em suas práticas visando atender aos interesses e necessidades de aprendizagem de seus alunos.

Nesta pesquisa estabelecemos como foco aspectos relacionados às grandezas comprimento/ tempo e medida. No entanto, consideramos fundamental o desenvolvimento de novas pesquisas a respeito do trabalho com grandezas como perímetro, área, volume e temperatura, e sobre como estes temas podem ser abordados com as crianças de Educação Infantil e anos iniciais do Ensino Fundamental.

5 As narrativas sobre os encontros e algumas práticas dos professores podem ser encontradas no site do grupo: http://gepromai.wixsite.com/gepromai 


\section{REFERÊNCIAS}

ALMEIDA, A. R. et al. Discutindo a Matemática em um grupo colaborativo: o caso GEProMAI. In: SEMINÁRIO FACULDADE DE EDUCAÇÃO "Educação Básica Brasileira": contexto e perspectiva, 9., 2014, PUC-Campinas. Anais... Campinas, 2014.

BAKHTIN, M. Estética da criação verbal. 4. ed. São Paulo: Martins Fontes, 2003.

BRASIL. Ministério da Educação. Secretaria de Educação Fundamental. Parâmetros curriculares nacionais: matemática. MEC/SEF: Brasília, 1998. $148 \mathrm{p}$.

BRASIL, Ministério da Educação. Conselho Nacional de Educação. Diretrizes Gerais para os Institutos Superiores de Educação (Dispõe sobre os Institutos Superiores de Educação, considerados os Art. 62 e 63 da Lei $n^{\circ}$ 9.394/96 e o Art. 9, § 2, letra h da Lei $n$ 9.131/95). Parecer CNE/CP $115 / 1999$ de 10 de agosto de 1999.

BRASIL. Ministério da Educação. Secretaria de Educação Básica. Diretoria de Apoio à Gestão Educacional. Pacto nacional pela alfabetização na idade certa: Grandezas e Medidas. Brasília: MEC, SEB, 2014.

CARAÇA, B. J. Conceitos fundamentais da Matemática. Lisboa: Bertrand, 1963.

CLANDININ, D. J.; CONNELLY, F. M. Pesquisa narrativa: experiência e história em pesquisa qualitativa. Tradução Grupo de Pesquisa Narrativa e Educação de Professores ILLE/UFU. Uberlândia: EDUFU, 2011.

CLEMENTS, D. H.; STEPHAN, M. Measurement in pre-K to grade 2 mathematics. In: CLEMENTS, D. H.; SARAMA, J.; DI BIASE, A.-M. (Eds.). Engaging young children in Mathematics: Standards for early childhood Mathematics education. Mahwah, $\mathrm{NJ}$ : LEA, 2004. p. 299-317.

COCHRAN-SMITH, M. A tale of two teachers: Learning to teach over time. Kappa Delta Pi Record, Indianapolis, v. 48, n. 3, p. 108-122, 2012.

CRECCI, V. M. Desenvolvimento profissional de educadores matemáticos participantes de uma comunidade fronteiriça entre escola e universidade. 2016. 325 f. Tese (Doutorado) - Universidade Estadual de Campinas, Campinas, 2016.

CUNHA, M. R. K. O estudo das elaborações de professores sobre o conceito de medida em atividade de ensino. 2008, f. 135. Tese (Doutorado em Educação) - Universidade Estadual de Campinas, Campinas-SP.
CURI, Edda. A matemática e os professores dos anos iniciais. São Paulo: Musa, 2005.

DAY, C. Formar docentes: cómo, cuándo y en qué condiciones aprende el professorado. Madrid: Narcea Ediciones, 2005.

FERNANDES, K. L. S.; PAULINO, L. C. S. Passo do curupira? Trabalhando medidas na educação infantil. In: SEMINÁRIO DA FACULDADE DE EDUCAÇÃO "Educação Básica Brasileira": contexto e perspectiva, 9. PUC-Campinas. Anais... Campinas, 2014.

FERREIRA, P. R. (Res)significação dos saberes docentes para educação infantil, a partir do diálogo com a etnomatemática. 2015. 121 fl. Dissertação (Mestrado) - Universidade Federal de São Carlos, Sorocaba, 2015.

FIORENTINI, D. Pesquisar práticas colaborativas ou pesquisar colaborativamente? In: BORBA, M. C.; ARAÚJO, J. L. (Org.). Pesquisa qualitativa em Educação Matemática. Belo Horizonte: Autêntica, 2004. p. 49-79.

A investigação em Educação Matemática desde a perspectiva acadêmica e profissional: desafios e possibilidades de aproximação. Cuadernos de Investigación y Formación en Educación Matemática, Costa Rica, ano 8, n. 11, p. 61-82, 2013.

FIORENTINI, D.; CARVALHO, D. L. O GdS como lócus de experiências de formação e aprendizagem docente. In: FIORENTINI, D; FERNANDES, F. L. P.; CARVALHO, D. L. Narrativas de práticas de aprendizagem docente em Matemática. São Carlos: Pedro \& João Editores, 2015. p. 15-37.

FLORES, M. A.; FLORES, M. O professor: agente de inovação curricular. 1998. Disponível em: <https:// repositorium.sdum.uminho.pt/bitstream/1822/657/1/ MariaAFlores.pdf>. Acesso em: 05 nov. 2017.

GAMA, R. P.; FIORENTINI, D. Formação continuada em grupos colaborativos: professores de Matemática iniciantes e as aprendizagens da prática profissional. Educação Matemática Pesquisa, São Paulo, v. 11, n. 3, 2009.

GATTI, B. A.; BARRETO, E. S. S. Professores do Brasil: impasses e desafios. Brasília: UNESCO, 2009. Disponível em: <http://unesdoc.unesco.org/ images/0018/001846/184682por.pdf $>$. Acesso em: 10 set. 2017

GATTI, B. A.; BARRETO, E. S. S.; ANDRÉ, Marli. Políticas docentes no Brasil. Brasília, DF: UNESCO, 2011. cap. 2, p. 23-30. Disponível em: <http://unes- 
doc.unesco.org/images/0021/002121/212183por.

pdf>. Acesso em: 10 out. 2017

GODINO, J. D.; BATANERO, C. M.; ROA, R. Medida de magnitudes y su didáctica para maestros. Granada: Universidad de Granada, Departamento de Didáctica de la Matemática, 2002.

GODOI, L. C. de O.; FIGUEIRÔA, S. F. de M. Dois pesos e duas medidas: uma proposta para discutir a natureza do sistema de unidades de medida na sala de aula. Caderno Brasileiro de Ensino de Física, Florianópolis, v. 25, n. 3, p. 523-545, 2008.

HARGREAVES, A. Os professores em tempos de mudança: o trabalho e a cultura dos professores na Idade Pós-Moderna. Porto: Porto Editora, 2001.

INHELDER, B.; PIAGET, J. A psicologia da criança. Rio de Janeiro: Difel, 2003.

LEÓN, A. T. El concepto de tiempo en niños y niñas de primer a sexto grado. Revista Latinoamericana de Ciencias Sociales, Niñez y Juventud, Manizales v. 9, n. 2, p. 869-884, 2011. Disponível em: <http:// www.scielo.org.co/pdf/rlcs/v9n2/v9n2a25.pdf>.

Acesso em 01 out. 2017.

LOPES, C. E. A educação estocástica na infância. Revista Eletrônica de Educação, São Carlos, v. 6, n. 1, p. 160-174, 2012.

LOPES, C. E.; GRANDO, R. C. Resolução de problemas na educação matemática para a infância. In: ENCONTRO NACIONAL DE DIDÁTICA E PRÁTICAS DE ENSINO-ENDIPE, 16., 2012, Campinas: Unicamp, 2012. p. 2-14. Disponível em: <http:// www.infoteca.inf.br/endipe/smarty/templates/arquivos_template/upload_arquivos/acervo/docs/3206b. pdf>. Acesso em: 20 set. 2016.

LORENZATO, S. Educação infantil e percepção matemática. Campinas (SP): Autores Associados, 2006.

MEGID, M. A. B. A. Formação inicial de professoras mediada pela escrita e pela análise de narrativas sobre operações numéricas. 2009, $219 \mathrm{ff}$. Tese. (Doutorado em Educação. Faculdade de Educação) - Universidade Estadual de Campinas, Campinas -SP.

MEGID, M. A. B. A.; ALMEIDA, A. R. Aprendizagem do professor em grupos colaborativos que ensinam matemática na infância: um olhar para grandezas e medidas. In: REUNIÃO ANUAL DA ANPED, 38., 2017, São Luís. Anais..., São Luís, 2017. Disponível em: <http://38reuniao.anped.org. $\mathrm{br} / \mathrm{sites} /$ default/files/resources/programacao/trabaIho_38anped_2017_GT19_1019.pdf>. Acesso em: 20 out. 2017.
MELLO, S. A. Infância e humanização: algumas considerações na perspectiva histórico-cultural. Perspectiva, Florianópolis, v. 25, n. 1, p. 57-82, jan./ jun. 2007.

MESTRINHO, N.; OLIVEIRA, H. A integração do Tangram na aula de Geometria: uma primeira abordagem ao conceito de área na formação inicial de professores dos primeiros anos. 2012. Disponível em: <https://repositorio.ul.pt/bitstream/10451/7076/1/Mestrinho_Oliveira_eiem.pdf>.

Acesso em: 31 de jul. de $20 \overline{15}$.

MOURA, A. R. L. A medida e a criança pré-escolar. 1995. 221 ff. Tese (Doutorado em Educação) - Faculdade de Educação, Universidade Estadual de Campinas, Campinas-SP.

MOURA A. R. L.; LORENZATO, S. O medir de crianças pré-escolares. Zetetiké, Campinas, v.9, n. 15-16, p. 7-41, jan./dez. 2001.

NACARATO, A. M.; MENGALI, B. L. S.; PASSOS, C. L. A matemática nos anos iniciais do ensino fundamental: tecendo fios do ensinar e do aprender. Belo Horizonte: Autêntica, 2009. (Coleção Tendências em Educação Matemática).

NYE, B.; KONSTANTOPOULOS, S; HEDGES, L. V. How large are teacher effects?. Educational evaluation and policy analysis. Thousand Oaks, v. 26, n. 3, p. 237-257, 2004.

PACHECO, J. A.; FLORES, M. A. Formação e avaliação de professores. Porto, Portugal: Porto Editora, 1999. (Coleção escola e saberes, n.16).

PASSOS, C. L. B. et al. Desenvolvimento profissional do professor que ensina Matemática: uma meta -análise de estudos brasileiros. Quadrante: Revista Teórica e de Investigação -APM, Portugal, v. XV, n. 1-2, p. 193-219, 2006.

PESCE, M. K.; ANDRÉ, M. E. D. A. Formação do professor pesquisador na perspectiva do professor formador. Formação Docente, Belo Horizonte, v. 04, n. 07, 2012, p. 39-50. Disponível em: <http://formacaodocente.autenticaeditora.com.br>. Acesso em: 10 out. 2017.

PONTE, J. P. Pesquisar para compreender e transformar a nossa própria prática. Educar em Revista, 24, 2004, p. 37-66.

PONTE, J. P. ; SERRAZINA, L. Didáctica da Matemática do $1 .^{\circ}$ ciclo. Lisboa: Universidade Aberta. In.: PORTUGAL. Ministério da Educação. Programa do Ensino Básico, 2000. disponível em: <www.esev.ipv. pt/mat1ciclo>. Acesso em: 05 nov. 2017. 
SARAIVA, M.; PONTE, J. P. O trabalho colaborativo e o desenvolvimento profissional do professor de Matemática. Quadrante: Revista Teórica e de Investigação - APM, Portugal, n. 12, v.2, p. 25-52, 2003.

SAVIANI, Dermeval. Política educacional brasileira: limites e perspectivas. Revista de Educação - PUCCampinas, n. 24, p. 07-16, jun. 2008.

SERRAZINA, M. L. O professor que ensina matemática e a sua formação: uma experiência em Portugal. Educação \& Realidade, Porto Alegre, v. 39, n. 4, p. 1051-1069, 2014.

SILVA, C. C. R. Construção de conceito de grandezas e medidas nos anos iniciais: comprimento, massa e capacidade. 2011, 230 ff.. Dissertação (Mestrado em Educação) - Faculdade de Educação, Universidade de Brasília, Brasília-DF.
SUBRAMANIAM, K. Prospective secondary mathematics teachers' pedagogical knowledge for teaching the estimation of length measurements. Journal of mathematics teacher education, v. 17, n. 2, p. 177-198, 2014.

ZEICHNER, K. M. The Ecology of Field Experience: Toward an Understanding of the Role of Field Experiences in Teacher Development. 1984. Disponível em: <https://eric.ed.gov/?id=ED240111>. Acesso em: 05 nov. 2017 